\title{
NANOSTRUCTURED FILMS OF PLASMA POLYMERIZED HEXAMETHYLDISILAZANE AND LACTIC ACID DEPOSITED BY ATMOSPHERIC PLASMA JET
}

\author{
'Zdeněk KRTOUŠ, ${ }^{2}$ Anton NIKIFOROV, ${ }^{2}$ rryna KUCHAKOVA, ${ }^{3} Z$ uzana KOLÁŘOVÁ-RAŠKOVÁ, \\ 3,4 Jana SEDLAŘíKOVÁ, ${ }^{1}$ Tereza KRETKOVÁ, ${ }^{1}$ Peter KUŠ, ${ }^{1}$ Ondřej KYLIÁN, ${ }^{1}$ Jaroslav KOUSAL \\ ${ }^{1}$ Charles University, Faculty of Mathematics and Physics, Prague, Czech Republic, EU \\ ${ }^{2}$ Faculty of Engineering and Architecture, Ghent University, Ghent, Belgium, EU \\ ${ }^{3}$ Tomas Bata University in Zlin, Centre of Polymer Systems, Zlin, Czech Republic, EU \\ ${ }^{4}$ Tomas Bata University in Zlin, Faculty of Technology, Zlin, Czech Republic, EU
}

https://doi.org/10.37904/nanocon.2019.8767

\begin{abstract}
In this work, composite layers of hexamethyldisilazane (HMDSN) and lactic acid (LA) were prepared using chemical vapor deposition process by a nitrogen atmospheric pressure plasma jet source. The HMDSN vapours were introduced into the plasma jet. Varying LA admixture was added into the jet in the form of aerosol.

The chemical composition, morphology and wettability of resulting films were studied. Infrared spectra and XPS analysis show both Si-O like and hydrocarbon structures. With increasing amount of LA admixture, the oxidation of the layers increases. The morphology of the films was measured with SEM. The films prepared with no LA have a foam-like structure. With increasing amount of LA the structure changes into more fractallike. The X-ray diffraction analysis suggests the presence of amorphous $\mathrm{SiO}_{2}$ domains in the films. The films exhibited superhydrophobic properties that can be modified by the post-treatment of the samples in DBD discharge.
\end{abstract}

Keywords: Lactic acid, hexamethyldisilazane, atmospheric plasma jet

\section{INTRODUCTION}

(Bio)degradable polymers, like polyethylene oxide and polylactic acid, are used in biomedical field [1], food industry, packaging or medicine [2]. For such applications, preparation of these materials in the form of thin films with controlled properties via plasma-based methods was found viable [3][4], including deposition in atmospheric pressure plasma [5].

Atmospheric pressure plasma jets have been used to produce thin films based on siloxanes [6][7] or silazanes [8][9]. While the monomer is more typically introduced into the discharge in the form of vapours, deposition from aerosols has also been demonstrated [10][11]. In this work, a combined deposition from HMDSN vapours and lactic acid aerosol in atmospheric pressure plasma jet has been studied.

\section{EXPERIMENTAL}

\subsection{Preparation of the films}

The films were prepared using atmospheric pressure DC plasma jet fed with nitrogen (Figure 1) [12][13]. The total $\mathrm{N}_{2}$ flow used was $7 \mathrm{l} / \mathrm{minstp}$. Of this, $0.1 \mathrm{l} / \mathrm{minstp}(100 \mathrm{sccm})$ was fed into the bubbler with HMDSN, effectively then carrying about $3 \mathrm{sccm}(0.025 \mathrm{ml} / \mathrm{min})$ of HMDSN. Lactic acid was supplied by a syringe pump into an ultrasonic sprayer (nebulizer). The resulting aerosol was carried with the rest of the $\mathrm{N}_{2}$ flow. The resulting mixture of $\mathrm{N}_{2}$, HMDSN vapours and LA aerosol was fed into the plasma jet. The plasma jet was 
operated at $10.2 \mathrm{kV}$ and $11.3 \mathrm{~mA}$. The deposition time was 5 minutes. The films were deposited on single-side polished silicon and gold-coated silicon.

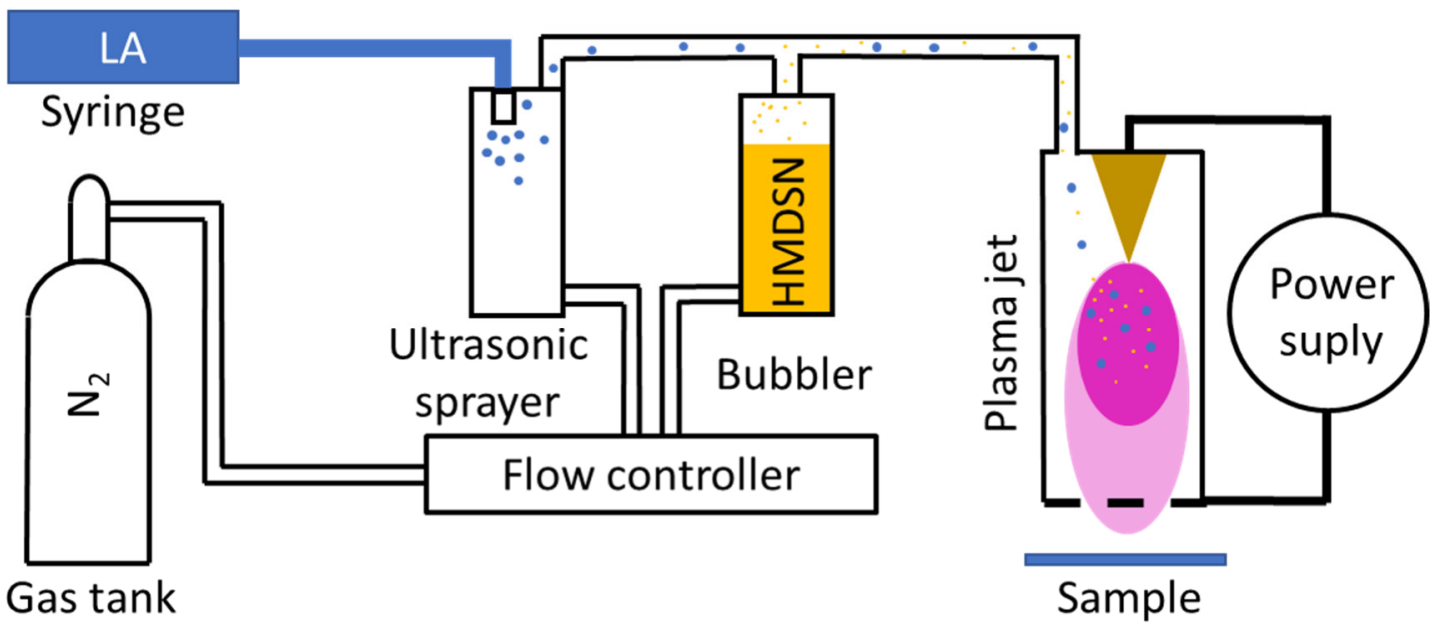

Figure 1 Scheme of deposition setup

\subsection{Characterization of composition and morphology of the films}

The chemical structure of the films was characterized using infrared spectroscopy (FTIR-RAS, Bruker Equinox 55) and X-ray photoelectron spectroscopy (XPS, Specs Phoibos 100). Morphology of the films was characterized by scanning electron microscopy (SEM, Tescan Mira III) and X-ray diffraction (XRD, Rigaku SmartLab). Water contact angle measurement and the dielectric barrier discharge (DBD, Ceplant) setup for post-treatment [14] were custom built.

\section{RESULTS AND DISCUSSION}

\subsection{Infrared spectra}

The infrared spectra of the films (Figure 2) generally resemble more the HMDSN monomer than LA, despite the relatively high LA input into the nebulizer. That can be probably explained by a worse transmission of the LA aerosol through the gas conduit in comparison with the HMDSN vapours. The most prominent features of the films can be attributed to bonds for silazanes ( $\mathrm{Si}-\mathrm{N}-\mathrm{Si}, \mathrm{N}-\mathrm{H}$ ), siloxanes ( $\mathrm{Si}-\mathrm{O}-\mathrm{Si}$ ) and alkyl-substituted silanes $\left(\mathrm{Si}-\mathrm{H}, \mathrm{Si}-\left(\mathrm{CH}_{3}\right)_{\times}, \mathrm{CH}_{\mathrm{x}}\right)$ with the presence of $\mathrm{OH}$ groups and a very small amount of $\mathrm{C}=\mathrm{O}$ bonds.

With increasing LA admixture most visible changes can be seen in the peak around $1100 \mathrm{~cm}^{-1}$. The shape of the peak shifts in favour of Si-O-Si bonds compared to nitrogen and carbon containing bonds, but the overall intensity of the peak decreases in comparison to the signal of Si-bound $\mathrm{CH}_{3}$ group.

\subsection{X-ray photoelectron spectroscopy}

The elemental composition of the films (Figure 3) was established using XPS. The amount of silicon in the films remains roughly constant. However, with increasing LA admixture, the amount of oxygen in the films increases and the amount of carbon and nitrogen decreases.

The shape of the high-resolution peaks was found to be too symmetrical to allow reliable assignment of all the various bonds possibly present in the films. The elemental composition of films on gold-coated substrates was measured as a double-check to avoid the influence of the silicon substrate on the apparent film composition. No significant difference to the composition of the films on pure silicon was found. 
a)

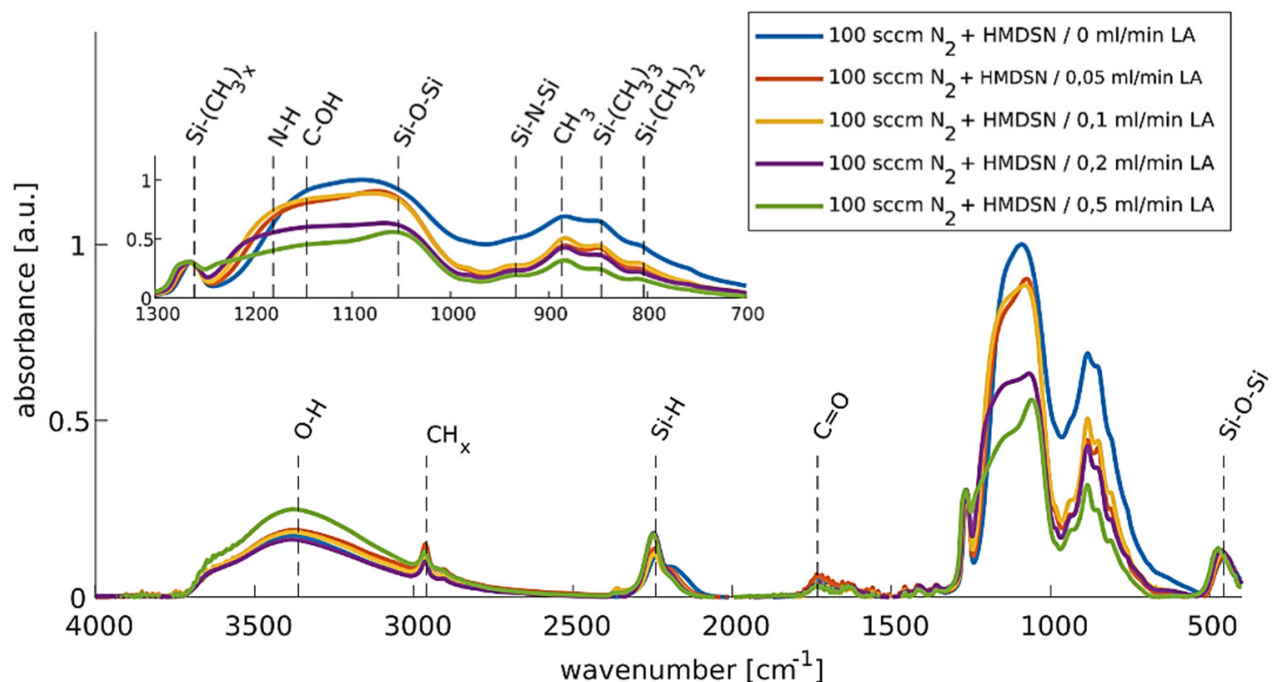

b)

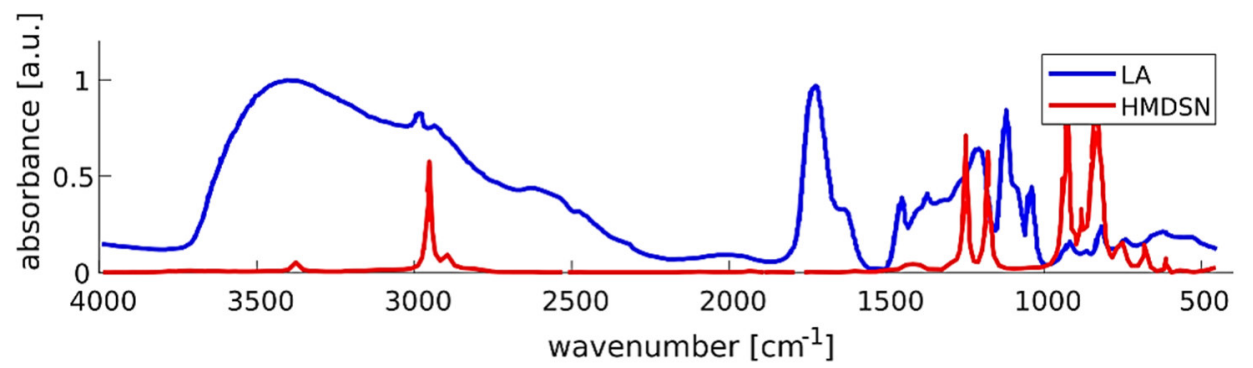

Figure 2 Infrared spectra, absorbance. a) Films prepared at a varying amount of lactic acid admixture. Intensity normalized on peak at $1270 \mathrm{~cm}^{-1}$. b) Tabulated spectra of lactic acid and hexamethyldisilazane.

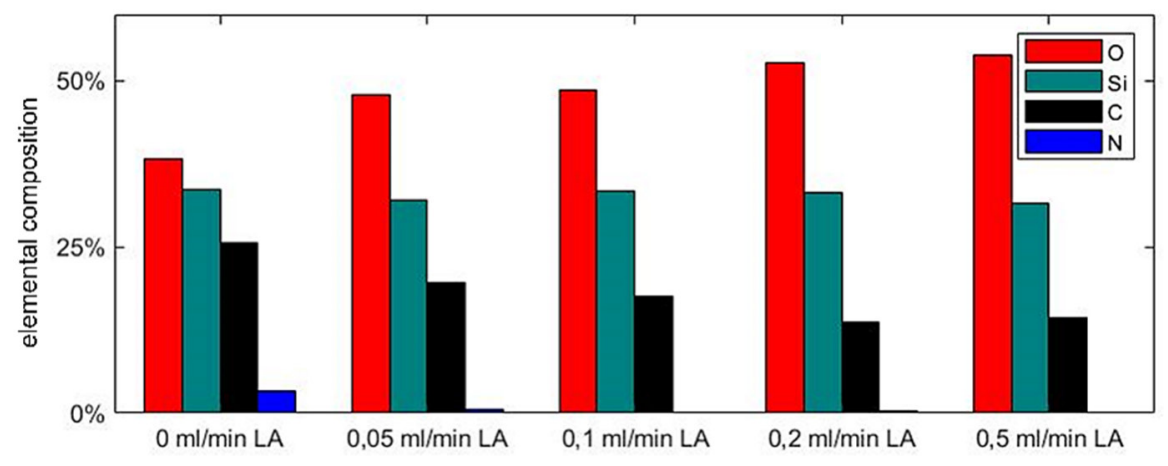

Figure 3 Elemental composition of films obtained by XPS for varying LA admixture.

\subsection{Chemical composition - summary}

The amount of silicon in the films seems to be almost independent of the concentration of LA added into the working gas. The concentration of nitrogen is very low (in HMDSN monomer the Si/N ratio is 2, in the films it is 8 or more) and for layers prepared with some LA, the nitrogen nearly disappears. We can also see that there is a lot of oxygen in all layers, including those without LA admixture. The plasma jet column itself carries in the ideal case only nitrogen with precursors, so we suppose that oxidation from the ambient air around the jet takes place in the process. An increase of the oxidation with increasing LA admixture shows a fragmentation of LA molecule, bringing more oxygen into the process. The plasma polymerization of lactic acid takes place in a very small amount if at all - if it were the case, the $C / O$ ratio would not drop with LA admixture. 
a)

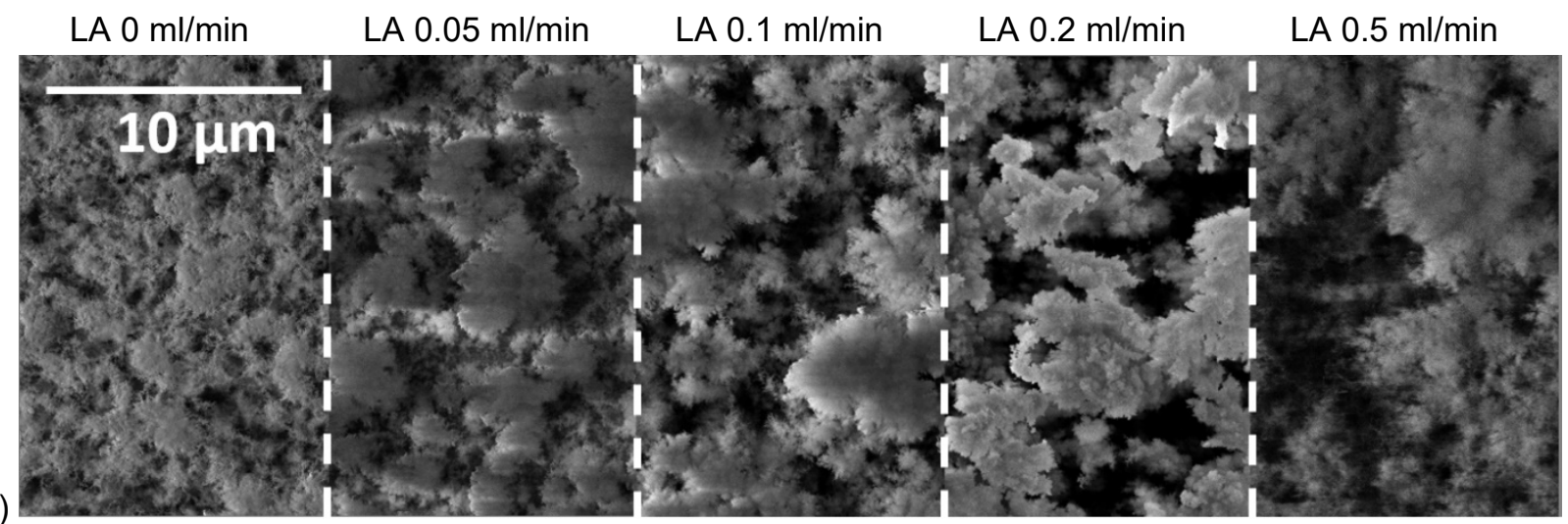

b)

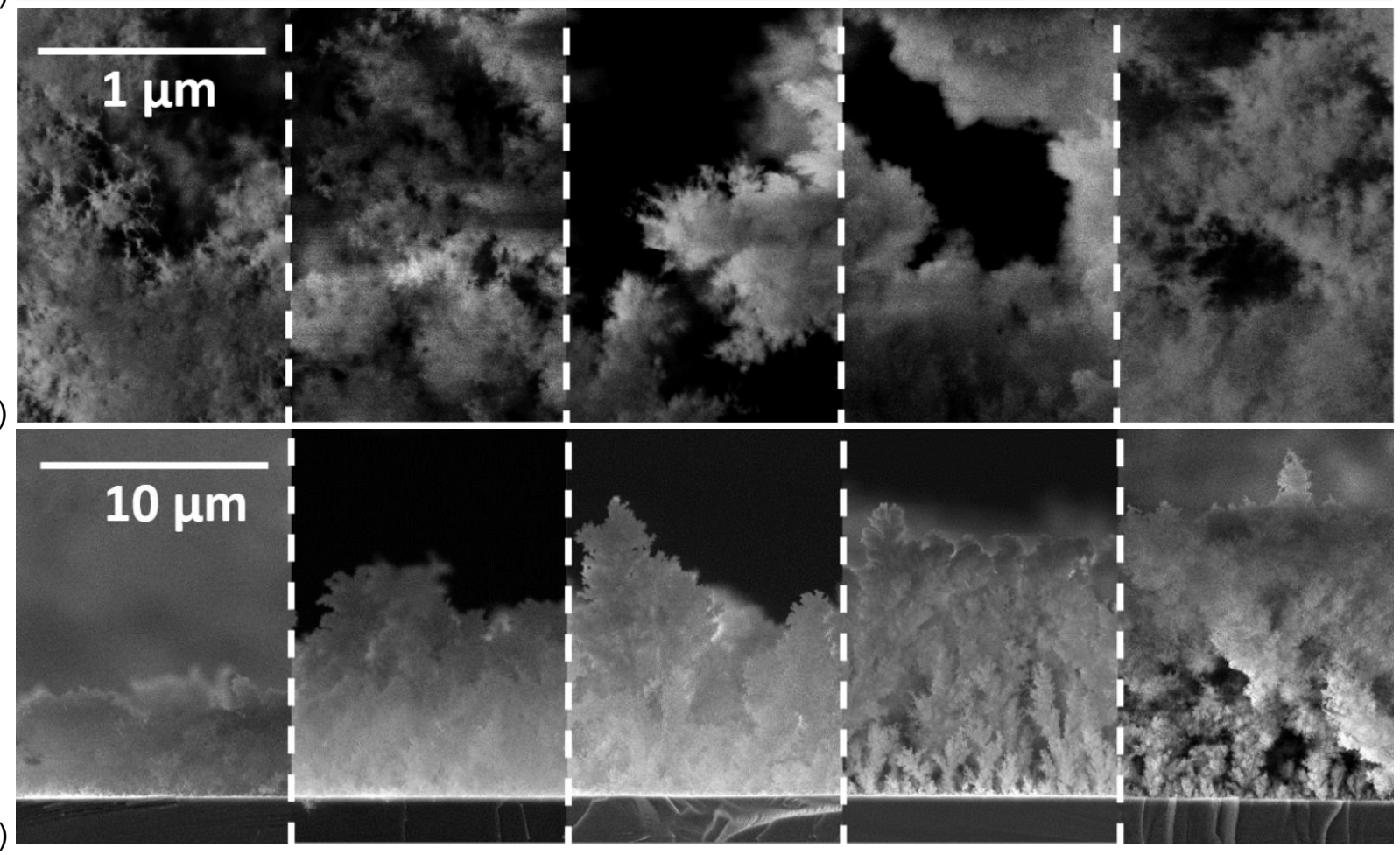

Figure 4 SEM images of the film for varying LA admixture a) top view b) close-up top view c) side view

\subsection{Morphology of the films}

The SEM images of the films are shown in (Figure 4). The films show a foam-like or fractal-like structure for lower or higher LA admixture, respectively. The size of the structures seems also to slightly increase with increasing LA admixture.

The film thickness increases with increasing LA amount input (Figure 5). However, the films then also appear to be visually less dense. The effective deposition rate of the films is $1-2 \mu \mathrm{m} / \mathrm{min}$.

Figure 5 Thickness of the films in dependence on the

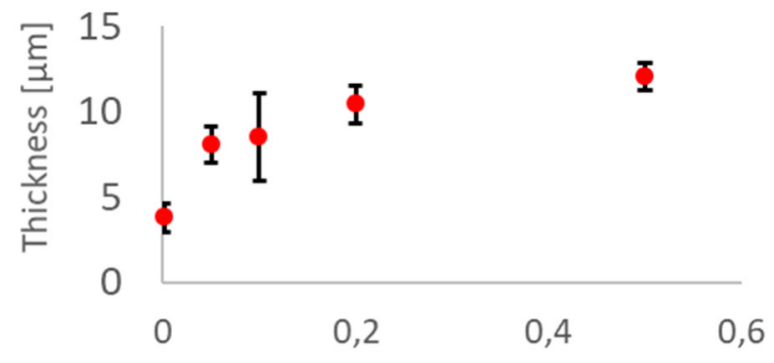
LA admixture

Amount of Lactid Acid [ml/min] 


\subsection{X-ray diffraction}

The X-ray diffraction data were obtained for the samples prepared at $0.1 \mathrm{ml} / \mathrm{min}$ and $0.2 \mathrm{ml} / \mathrm{min}$ of LA admixture. A weak peak around $2 \Phi=23^{\circ}$ was detected. The corresponding lattice constant can match $\mathrm{SiO}_{2}$ domains that can be present in the structure of the films. The width of the peak $\left(\sim 10^{\circ} \mathrm{FWHM}\right)$ suggests that these domains are amorphous.

\subsection{Wettability properties of the films and DBD treatment of the films}

The films were found to be superhydrophobic and slippery (water contact angle $\sim 180^{\circ}$, no hysteresis in advancing/receding contact angle). Films prepared with 0 and $0.2 \mathrm{ml} / \mathrm{min}$ LA admixture were treated with dielectric barrier discharge in air. After treatment with the discharge with a power density of $3 \mathrm{~W} / \mathrm{cm}^{2}$ for $10 \mathrm{~s}$ these films were found to be superhydrophilic. This switching between the extremes of wetting behaviour of nanostructured films due to chemical changes on their surface have previously been demonstrated on other nanostructured films [15][16].

\section{CONCLUSIONS}

Thin films from hexamethyldisilazane and lactic acid have been prepared using atmospheric pressure plasma jet. The LA is found to be strongly fragmented in the discharge. The resulting nanostructured films have a general composition of oxidized organosilicones with domains of $\mathrm{SiO}_{2}$. The films exhibit superhydrophobic properties.

\section{ACKNOWLEDGEMENTS}

This work was supported by the grant 17-10813S of the Czech Science Foundation.

\section{REFERENCES}

[1] LENDLEIN, A., SISSON, A. Handbook of Biodegradable Polymers: Isolation, Synthesis, Characterization and Applications, Weinhem: John Wiley \& Sons, 2011

[2] KUCHARCZYK, P., HNATKOVA, E., DVORAK, Z., SEDLARIK, V. Novel aspects of the degradation process of PLA based bulky samples under conditions of high partial pressure of water vapour. Polymer Degradation and Stability, 2013, vol. 98, pp. 150-157

[3] CHOUKOUROV, A., GORDEEV, I., ARZHAKOV, D., ARTEMENKO, A., KOUSAL, J., KYLIAN, O., SLAVINSKA, D., BIEDERMAN, H. Does Cross-Link Density of PEO-Like Plasma Polymers Influence their Resistance to Adsorption of Fibrinogen? Plasma Processes and Polymers, 2011, vol. 9, no. 1, pp. 48-58

[4] KOLÁŘOVÁ RAŠKOVÁ, Z., KOUSAL, J., STLOUKAL, P., KRTOUŠ, Z. Hydrolysis of PLA-like Plasma Polymer Films with Varying Degree of Crosslinking. Plasma Physics and Technology, 2016, vol. 3, no. 3, pp. 168-171

[5] LAURENT, M., KOEHLER, J., SABBATIER, G., HOESLI, C. A., GHERARDI, N., LAROCHE, G. Atmospheric Pressure Plasma Polymer of Ethyl Lactate: In Vitro Degradation and Cell Viability Studies. Plasma Processes and Polymers, 2016, vol. 13, pp. 711-721

[6] LIN, Y.-S., WENG M.-S., CHUNG, T.-W., HUANG, C. Enhanced surface hardness of flexible polycarbonate substrates using plasma-polymerized organosilicon oxynitride films by air plasma jet under atmospheric pressure. Surface \& Coatings Technology, 2011, vol. 205, pp. 3856-3864

[7] DENG, X., NIKIFOROV, A. Y., DE GEYTER, N., MORENT, R., LEYS, C. Deposition of a TMDSO-Based Film by a Non-Equilibrium Atmospheric Pressure DC Plasma Jet. Plasma Processes and Polymers. 2013, vol. 10, pp. 641-648

[8] HUANG, Q., XIONG, L., DENG, X., SHU, Z., CHEN, Q., BAO, B., CHEN, M., XIONG, Q. Super-hydrophobic film deposition by an atmospheric-pressure plasma process and its anti-icing characteristics. Plasma Science and Technology, 2019, vol. 21, pp. 055502 
[9] KODAIRA, F. V. P., RICCI CASTRO, A. H., PRYSIAZHNYI, V., MOTA, R. P., QUADE, A., KOSTOV, K. G. Characterization of plasma polymerized HMDSN films deposited by atmospheric plasma jet, Surface \& Coatings Technology, 2017, vol. 312, pp. 117-122

[10] O’NEILL, L., O'SULLIVAN, C., Polymeric Coatings Deposited From an Aerosol-Assisted Non-thermal Plasma Jet. Chemical Vapor Deposition, 2009, vol. 15, pp. 21-26

[11] BARLETTA, F., LIGUORI, A., LEYS, C., COLOMBO, V., GHERARDI, M., NIKIFOROV, A. Novel method for NHrich coatings engineering by means of aerosol assisted atmospheric pressure plasma deposition, Materials Letters, 2018, vol. 214, pp. 76-79

[12] DENG, X. L., NIKIFOROV, A. Y., VANRAES, P., LEYS, C. Direct current plasma jet at atmospheric pressure operating in nitrogen and air. Journal of Applied Physics, 2013, vol. 113, pp. 023305

[13] DENG, X., NIKIFOROV, A. Y., COENYE, T., COOLS, P., AZIZ, G., MORENT, R., DE GEYTER, N., LEYS. C. Antimicrobial nano-silver nonwoven polyethylene terephthalate fabric via an atmospheric pressure plasma deposition process, Scientific Reports, 2015, vol. 5, pp. 10138

[14] KUZMINOVA A., SHELEMIN, A., KYLIÁN, O., CHOUKOUROV, A., VALENTOVÁ, H., KRAKOVSKÝ, I., NEDBAL, J., SLAVÍNSKÁ, D., BIEDEMAN, H. Study of the effect of atmospheric pressure air dielectric barrier discharge on nylon 6,6 foils. Polymer Degradation and Stability, 2014, vol. 110, pp. 378-388

[15] BERNDT, J., ACID, H., KOVACEVIC, E., CACHONCINLLE, C., STRUNSKUS, T., BOUFENDI, L. Deposition and tuning of nanostructured hydrocarbon deposits: From superhydrophobic to superhydrophilic and back. Journal of Applied Physics, 2013, vol. 113, pp. 063302

[16] KUZMINOVA, A., SHELEMIN, A., KYLIÁN, O., PETR, M., KRATOCHVÍL, J., SOLAŘ, P., BIEDERMAN, H. From super-hydrophilic to super-hydrophobic surfaces using plasma polymerization combined with gas aggregation source of nanoparticles, Vacuum, 2014, vol. 110, pp. 58-61 